\title{
Housing investment in Spain: has it been the main engine of growth?
}

\author{
Carolina Cosculluela Martínez ${ }^{\mathrm{a},{ }^{*}}$ and Rafael Flores de Frutos ${ }^{\mathrm{b}}$ \\ ${ }^{a}$ Departamento de Economía Aplicada I, Facultad de Ciencias Jurídicas y Sociales, \\ Universidad Rey Juan Carlos, $P^{o}$ de los Artilleros, s/n 28032, Madrid, Spain \\ ${ }^{b}$ Departamento de Fundamentos de Análisis Económico II. Facultad de Ciencias \\ Económicas. Universidad Complutense de Madrid. Campus de Somosaguas, 28223, \\ Madrid, Spain
}

*Mailing address: carolina.cosculluela@urjc.es

\begin{abstract}
This paper studies dynamic responses of employment and GDP growth to a permanent, unitary shock in the housing capital stock for the Spanish economy. It quantifies the importance of this variable in the boom experienced by the Spanish economy during the pre-crisis years. Results confirm that building industry has been the most important engine for output and labour growth.
\end{abstract}

\section{RESUMEN}

En este trabajo se estudia la respuesta dinámica del crecimiento del empleo y del PIB de la economía española ante un choque permanente unitario en el stock de capital vivienda. Se cuantifica la importancia del capital vivienda en el boom económico experimentado en los años anteriores de la crisis actual. Los resultados confirman que la industria de la construcción ha sido el acicate más importante para el crecimiento del empleo y del PIB.

KEY WORDS: Stock de Capital (Capital Stock), Capital vivienda (Housing Capital), Empleo (Labour), Producto Interior Bruto (Gross Domestic Product), crecimiento (growth), inversión (Investment).

CÓDIGOS JEL: C32, H54, C51, C53, E22 


\section{Introduction}

According to BBVA-IVIE new data set on Spanish capital stock, the housing capital stock in 2005 , last year available, represented a $45.37 \%$ of the total capital stock.

High borrowing capacity from Spanish families, low interest rates and a kind of "animal" preferences for bricks have been the explanations given for the boom in the demand for houses.

During the last decade, there has been a high development of the building industry, allowing for unemployment rates never seen before in Spain, lower than 10\%. The profession wisdom is that the building industry has been "The Engine" of the Spanish economy during this period.

The story looks likely but disaggregated econometric estimations of the effects of housing capital stock are scarce. While the effects of infrastructure capital stock or investment has been largely studied since Aschauer (1989a, 1989b) until Pereira and Flores (1999), Pereira (2000), or Pereira and Andraz $(2005,2010)$ in this decade, for the Spanish economy, econometric analysis on the effects of housing capital stock are difficult to find.

In this paper, the dynamic effects of housing capital stock on the Spanish employment and GDP growth are estimated. Thus, the hypothesis of building industry being the main engine for growth is evaluated.

To suit the current problem, the conceptual framework used in Flores et al (1998) is modified. These authors evaluated the effects of public capital stock $(P K)$ on employment $(L)$ and GDP $(Y)$ growth, for the Spanish economy. They showed that when studying the dynamics effects of a variable $(P K)$ on a set of others $(L$ and $Y)$ it is not necessary to build a complete dynamic structural model, but only a conveniently orthogonalized reduced form of it.

To find this reduced form is feasible if the contemporaneous correlations, between the variable whose effects have to be studied $(P K)$ and the rest $(L$ and $Y$ ) can be interpreted as instant causal relationships going in a particular direction. Such a procedure has the advantage of imposing just a minimum amount of assumptions on the model structure, avoiding the risk of dynamic misspecification. The goal is to avoid unnecessary, a priori, constrains on the statistical properties of data, due to an unnecessary constrained theoretical model.

The conceptual framework proposed in Flores et al (1998) allows for nonstationary time series, co-integration relationships, and any kind of dynamics including feedbacks relationships.

The rest of the paper is organized as follows. Section II shows the new version of the theoretical framework. Section III presents the time series used, their statistical properties and the empirical estimation of the theoretical model. Section IV discusses the impulse response functions (IRFs) of output and employment. Finally, Section V provides the concluding remarks. 


\section{Theoretical Framework}

The framework used by Flores et al (1998) is adapted to the present problem. Now, the vector of relevant variables in this research is $\mathrm{W}_{\mathrm{t}}=\left(Y_{t}, L_{t}, K_{1_{t}}, \bar{K}_{1_{t}}\right)^{\prime}$, all referring to the Spanish economy. Where:

$Y_{t}:$ is the Gross Domestic Product (GDP)

$L_{t}$ : Total employment

$K_{1_{t}}:$ Housing Capital Stock

$\bar{K}_{1}$ : Complementary Capital Stock, computed as the difference between the Total Capital Stock and the Housing Capital Stock.

The vector of lowercase variables $\mathrm{w}_{\mathrm{t}}=\left(y_{t}, l_{t}, \bar{k}_{1_{t}}, k_{1_{t}}\right)^{\prime}$ represents the vector of firstdifferenced logged variables of $\mathrm{W}_{\mathrm{t}}$. As it is shown later in this paper, $\mathrm{w}_{\mathrm{t}}$ it is a vector of integrated variables of order $1, \mathrm{I}(1)$ variables. The objective is to estimate the IRFs of $y_{t}$ and $l_{t}$ to a permanent unitary shock in $k_{1_{t}}$.

Those IRFs can be obtained from the dynamic structural equations set, represented in compact notation, by:

$$
\Pi^{*}{ }_{\mathrm{w}}(\mathrm{B}) \mathrm{w}_{\mathrm{t}}=\mathrm{a}_{\mathrm{t}}^{*}
$$

where:

- $\Pi^{*}{ }_{\mathrm{w}}(\mathrm{B})$ is a polynomial matrix ${ }^{1}$ in $\mathrm{B}$, the lag operator:

$$
\Pi^{*}{ }_{\mathrm{w}}(\mathrm{B})=\Pi_{0, \mathrm{w}}^{*}-\Pi_{1, \mathrm{w}}^{*} \mathrm{~B}-\Pi_{2, \mathrm{w}}^{*} \mathrm{~B}^{2}-\cdots
$$

Whose elements are $(4 \times 4)$ coefficients matrices.

- $\mathrm{a}_{\mathrm{t}}^{*}$ is a $(4 \times 1)$ vector of structural shocks, which follows a white-noise vector process, with a diagonal contemporaneous covariance matrix $\Sigma^{*}$.

Alternatively, and assuming invertibility, (1) can be expressed as:

$$
\mathrm{w}_{\mathrm{t}}=\psi(B) \mathrm{a}_{\mathrm{t}}^{*}
$$

\footnotetext{
${ }^{1}$ The roots of the determinant of $\Pi^{*}{ }_{w}(\mathrm{~B})$ must lie on or outside the unit circle.
} 
where:

- $\psi(B)=\left(\Pi^{*}{ }_{w}(B)\right)^{-1}=\psi_{0}+\psi_{1} B+\psi_{2} B^{2}+\cdots$

With each $\psi_{\mathrm{j}}$ being a $(4 \times 4)$ coefficients matrix.

The IRFs of $y_{t}$ to a shock in $k_{1 t}$ would be given by the sequence of coefficients, in position $(1,4)$ of $\psi_{0}, \psi_{1}, \psi_{2}, \ldots$ matrices. Thus, the IRFs of $l_{t}$ to a shock in $k_{1 t}$ would be represented by the position $(2,4)$ in the sequence of matrices $\psi_{0}, \psi_{1}, \psi_{2}, \ldots$

To estimate $\psi(B)$ in a consistent manner, the exact identification of $\Pi_{0, \mathrm{w}}^{*}$ is needed. That is, it is necessary to be able to pass, biunovocally, from (1) to (3):

$$
\Pi_{\mathrm{w}}(\mathrm{B}) \mathrm{w}_{\mathrm{t}}=\mathrm{a}_{\mathrm{t}}
$$

where:

- $\Pi_{\mathrm{w}}(\mathrm{B})=\left(\Pi_{0, \mathrm{w}}^{*}\right)^{-1} \Pi_{\mathrm{w}}^{*}(\mathrm{~B})$

- $\mathrm{a}_{\mathrm{t}}=\left(\Pi_{0, \mathrm{w}}^{*}\right)^{-1} \mathrm{a}_{\mathrm{t}}^{*}$

with:

$$
\mathrm{E}\left(\mathrm{a}_{\mathrm{t}}, \mathrm{a}_{\mathrm{t}}^{\prime}\right)=\Sigma=\left(\Pi_{0, \mathrm{w}}^{*}\right)^{-1} \Sigma^{*}\left(\Pi_{0, \mathrm{w}}^{*^{\prime}}\right)^{-1}
$$

That is, $\Pi^{*}{ }_{w}(\mathrm{~B})$ can be estimated if there is only one matrix which diagonalizes $\Sigma$, that is $\Pi_{0, \mathrm{w}}^{*}$.

Equation (3) is the nonstationary VARMA process for the I(1) vector of variables in $w_{t}$, which can be approximated by a finite $\operatorname{VAR}(\mathrm{p})$ process. The process (3) can be estimated directly from the data set, using standard techniques.

The matrix $\Pi_{0, \mathrm{w}}^{*}$ can be estimated from the estimation of $\Sigma$ as long as there are enough restrictions on it. Once $\Pi_{0, \mathrm{w}}^{*}$ has been estimated, $\widehat{\Pi}_{\mathrm{w}}^{*}(\mathrm{~B})$ can be obtained from:

$$
\widehat{\Pi}_{\mathrm{w}}^{*}(\mathrm{~B})=\widehat{\Pi}_{0, \mathrm{w}}^{*} \widehat{\Pi}_{\mathrm{w}}(\mathrm{B})
$$

Finally, the estimates of the IRFs can be obtained from:

$$
\widehat{\psi}(\mathrm{B})=\left[\widehat{\Pi}_{\mathrm{w}}^{*}(\mathrm{~B})\right]^{-1}
$$


The key in order to find the responses of $y_{t}$ and $l_{t}$ to a shock in $k_{1_{t}}$ consists in introducing enough restrictions in $\Pi_{0, \omega}^{*}$ for this matrix to become the particular matrix able to diagonalize $\Sigma$.

Each coefficient in $\Pi_{0, \omega}^{*}$ represents the instantaneous structural response of a variable to a shock in other variable included in $\mathrm{w}_{\mathrm{t}}$. However, for our purpose, the complete identification of $\Pi_{0, \omega}^{*}$ it is not necessary, that is, it is not necessary to identify every element in $\mathrm{a}_{\mathrm{t}}^{*}$.

In $\mathrm{w}_{\mathrm{t}}$ it can be distinguished two types of variables, vector $\mathrm{z}_{\mathrm{t}}=\left(y_{t}, l_{t}\right)^{\prime}$ and vector $\mathrm{k}_{\mathrm{t}}=\left(k_{1}, \bar{k}_{1 t}\right)^{\prime}$. The vector $\mathrm{k}_{\mathrm{t}}$ is made on variables more rigid than variables in $\mathrm{z}_{\mathrm{t}}$; that is, $\mathrm{z}_{\mathrm{t}}$ variables responses are faster than responses of $\mathrm{k}_{\mathrm{t}}$. It seems reasonable to think that a shock in $\mathrm{k}_{\mathrm{t}}$ (in period $\mathrm{t}$ ) would have both instantaneous and lagged effects on the variables in $\mathrm{z}_{\mathrm{t}}$. However, a shock in period $\mathrm{t}$ in any variable of $\mathrm{z}_{\mathrm{t}}$ would only cause lagged responses of $\mathrm{k}_{\mathrm{t}}$ variables. It means that $\mathrm{k}_{\mathrm{t}}$ variables need time to react to changes in $y_{t}$ or $l_{t}$.

Thus, $\mathrm{k}_{\mathrm{t}}$ levels are determined by past values of $\mathrm{z}_{\mathrm{t}}$, while $\mathrm{z}_{\mathrm{t}}$ values are determined by past and present values of $\mathrm{k}_{\mathrm{t}}$.

Formally, the behaviour of vectors $\mathrm{z}_{\mathrm{t}}$ and $\mathrm{k}_{\mathrm{t}}$ can be represented as:

$$
\begin{gathered}
\mathrm{z}_{\mathrm{t}}=\mathrm{v}_{\mathrm{z}}(\mathrm{B}) \mathrm{k}_{\mathrm{t}}+\mathrm{N}_{\mathrm{z}_{\mathrm{t}}} \\
\pi_{\mathrm{z}}(\mathrm{B}) \mathrm{N}_{\mathrm{z}_{\mathrm{t}}}=\alpha_{\mathrm{z}_{\mathrm{t}}} \\
\mathrm{k}_{\mathrm{t}}=\mathrm{v}_{\mathrm{k}}(\mathrm{B}) \mathrm{z}_{\mathrm{t}}+\mathrm{N}_{\mathrm{k}_{\mathrm{t}}} \\
\pi_{\mathrm{k}}(\mathrm{B}) \mathrm{N}_{\mathrm{k}_{\mathrm{t}}}=\alpha_{\mathrm{k}_{\mathrm{t}}}
\end{gathered}
$$

Where $\mathrm{v}_{\mathrm{z}}(\mathrm{B})$ and $\mathrm{v}_{\mathrm{k}}(\mathrm{B})$ are $(2 \times 2)$ matrices of stable transfer functions:

$$
\mathrm{v}_{\mathrm{z}}(\mathrm{B})=\left(\begin{array}{cc}
\mathrm{v}_{\bar{k}_{\bar{k}_{1 t}}}(\mathrm{~B}) & \mathrm{v}_{y_{k_{1}}}(\mathrm{~B}) \\
\mathrm{v}_{l_{\bar{k}_{1 t}}}(\mathrm{~B}) & \mathrm{v}_{l_{k_{1 t}}}(\mathrm{~B})
\end{array}\right) \text { and } \mathrm{v}_{\mathrm{K}}(\mathrm{B})=\left(\begin{array}{cc}
\mathrm{v}_{\bar{k}_{1 y_{t}}}(\mathrm{~B}) & \mathrm{v}_{\bar{k}_{1 l_{t}}}(\mathrm{~B}) \\
\mathrm{v}_{k_{1_{y_{t}}}}(\mathrm{~B}) & \mathrm{v}_{k_{1_{l}}}(\mathrm{~B})
\end{array}\right)
$$

Each transfer function in $v_{\mathrm{z}}(\mathrm{B})$ representing the unidirectional response function of each variable $y_{t}$ and $l_{t}$ to shocks in $\mathrm{k}_{\mathrm{t}}$.

At the same time, $\mathrm{k}_{\mathrm{t}}$ variables have different yield. It is reasonable to consider that other than housing capital infrastructures $\bar{k}_{1_{t}}$ takes longer to react than housing capital infrastructures $k_{1_{t}}$. 
The housing capital stock $k_{1_{t}}$ will react instantaneously (in the same year) to changes in other infrastructures $\bar{k}_{1 t}$ and will continue reacting to those changes over several years. However, other infrastructures $\bar{k}_{1_{t}}$ will only present lagged reactions to changes in housing capital stock, i.e. they would not react in the same year. Thus, shocks in housing capital stock will produce changes in other infrastructures such as highways, railways etc. But those changes will take place from the second year onwards, not in the same year in which the shock in housing capital stock is produced. It is important to note that the empirical analysis will show that no significant contemporaneous correlations between these variables are found, and therefore, this assumption will not be necessary.

This idea in mathematic notation can be represented as:

$$
\begin{gathered}
\mathrm{k}_{\mathrm{t}}=\mathrm{v}_{\mathrm{k}}(\mathrm{B}) \mathrm{z}_{\mathrm{t}}+\mathrm{N}_{\mathrm{k}_{\mathrm{t}}} \\
\pi_{\mathrm{k}}(\mathrm{B}) \mathrm{N}_{\mathrm{k}_{\mathrm{t}}}=\alpha_{\mathrm{k}_{\mathrm{t}}}
\end{gathered}
$$

with

$$
\mathrm{E}\left(\alpha_{\mathrm{k}_{\mathrm{t}}} \alpha_{\mathrm{k}_{\mathrm{t}}}^{\prime}\right)=\Sigma_{\mathrm{k}}=\mathrm{P}_{\mathrm{k}} \Sigma_{\mathrm{k}}^{*} \mathrm{P}_{\mathrm{k}}^{\prime}
$$

Where $P_{K}=\left(\begin{array}{cc}1 & 0 \\ -\beta & 1\end{array}\right)$ is the diagonalization matrix for $\Sigma_{k}$ and $\beta$ is the slope in regres$\operatorname{sion}(13)$.

$$
\alpha_{\mathrm{k}_{\mathrm{t}}}=\beta \alpha_{\overline{\mathrm{k}}_{\mathrm{t}}}+\alpha_{\mathrm{k}_{\mathrm{t}}}^{*}
$$

Taking into account this assumption (10) would be:

$$
\mathrm{P}_{\mathrm{k}} \Pi_{\mathrm{k}}(\mathrm{B}) \mathrm{k}_{\mathrm{t}}=\mathrm{P}_{\mathrm{k}} \Pi_{\mathrm{k}}(\mathrm{B}) v_{\mathrm{k}}(\mathrm{B}) \mathrm{z}_{\mathrm{t}}+\mathrm{P}_{\mathrm{k}} \alpha_{\mathrm{k}_{\mathrm{t}}}
$$

or

$$
\mathrm{P}_{\mathrm{k}} \Pi_{\mathrm{k}}(\mathrm{B}) \mathrm{k}_{\mathrm{t}}=\mathrm{P}_{\mathrm{k}} \Pi_{\mathrm{k}}(\mathrm{B}) v_{\mathrm{k}}(\mathrm{B}) \mathrm{z}_{\mathrm{t}}+\alpha_{\mathrm{k}_{\mathrm{t}}}^{+}
$$

with

$$
\mathrm{E}\left(\alpha_{\mathrm{k}_{\mathrm{t}}}^{+}, \alpha_{\mathrm{k}_{\mathrm{t}}}^{+}\right)=\Sigma_{\mathrm{k}}^{+}
$$


diagonal.

Equations (9) and (15) in compact notation would be:

$$
\left[\begin{array}{cc}
\Pi_{\mathrm{z}}(\mathrm{B}) & -\Pi_{\mathrm{z}}(\mathrm{B}) v_{\mathrm{z}}(\mathrm{B}) \\
-\mathrm{P}_{\mathrm{k}} \Pi_{\mathrm{k}}(\mathrm{B}) v_{\mathrm{k}}(\mathrm{B}) & \Pi_{\mathrm{k}}(\mathrm{B}) v_{\mathrm{k}}(\mathrm{B})
\end{array}\right] \times\left[\begin{array}{c}
\mathrm{z}_{\mathrm{t}} \\
\mathrm{k}_{\mathrm{t}}
\end{array}\right]=\left(\begin{array}{c}
\alpha_{\mathrm{z}_{\mathrm{t}}} \\
\alpha_{\mathrm{k}_{\mathrm{t}}}^{+}
\end{array}\right)
$$

with

$$
\mathrm{E}\left[\left(\begin{array}{c}
\alpha_{\mathrm{z}_{\mathrm{t}}} \\
\alpha_{\mathrm{k}_{\mathrm{t}}}^{+}
\end{array}\right)\left(\begin{array}{ll}
\alpha_{\mathrm{z}_{\mathrm{t}}}^{\prime} & \alpha_{\mathrm{k}_{\mathrm{t}}}^{+\prime}
\end{array}\right)^{\prime}\right]=\left[\begin{array}{cc}
\Sigma_{\mathrm{z}} & 0 \\
0 & \Sigma_{\mathrm{k}}^{+}
\end{array}\right]
$$

This model is similar to (1), the difference between them is the dependence of the variables in $\alpha_{z_{\mathrm{t}}}$, that is the non diagonal character of $\Sigma_{z}$. However it will be possible to estimate the responses functions of each one of the elements of $z_{t}$ to a shock in $k_{1_{t}}$.

Model (16)-(17) in compact notation would be:

$$
\Pi^{+}(\mathrm{B}) \mathrm{w}_{\mathrm{t}}=\alpha_{\mathrm{t}}^{+}
$$

with

$$
\mathrm{E}\left(\alpha_{\mathrm{t}}^{+}{\alpha_{\mathrm{t}}^{+}}^{\prime}\right)=\Sigma^{+}
$$

block diagonal.

Since $\Pi^{+}(0)=\left[\begin{array}{cc}\mathrm{I} & -v_{\mathrm{z} 0} \\ 0 & \mathrm{P}_{\mathrm{k}}\end{array}\right] \neq \mathrm{I}$, the stochastic multivariate model (16) is not normalized in the sense of Alavi (1981). However, it can be normalized by pre-multiplying (18) by $\left[\Pi^{+}(0)\right]^{-1}$ :

$$
\left[\Pi^{+}(0)\right]^{-1} \Pi^{+}(\mathrm{B}) \mathrm{w}_{\mathrm{t}}=\left[\Pi^{+}(0)\right]^{-1} \alpha_{\mathrm{t}}^{+}
$$

where (20) is equal to (3) with

$$
\begin{aligned}
\Pi(B) & =\left[\Pi^{+}(0)\right]^{-1} \Pi^{+}(B) \\
a_{t} & =\left[\Pi^{+}(0)\right]^{-1} \alpha_{t}^{+}
\end{aligned}
$$


Estimating (3) and its corresponding instant variance-covariance matrix, it allows to estimate in a consistent manner all the parameters in (18) and $(19)^{2}$, that is, $\left[\Pi^{+}(\mathrm{B})\right]$ and $\Sigma^{+}$ which are similar to model $(1)$; and from them, the IRFs. Positions $(1,4)$ and $(2,4)$ of the polynomial elements in (22) will give the response functions of $y_{t}$ and $l_{t}$, respectively.

$$
\mathrm{w}_{\mathrm{t}}=\Psi^{+}(\mathrm{B}) \alpha_{\mathrm{t}}^{+}
$$

with

$$
\Psi^{+}(\mathrm{B})=\left[\Pi^{+}(\mathrm{B})\right]^{-1}=\Psi_{0}^{+}+\Psi_{1}^{+} \mathrm{B}+\Psi_{2}^{+} \mathrm{B}^{2}+\cdots
$$

In the following section, expressions (20) and (23) are estimated.

\section{Estimation of the Theoretical Model.}

\section{The Data}

It has been used yearly data of the Spanish economy for the period 1977/2005:

$Y_{t}$ : Gross Domestic Product (GDP) obtained from the World Bank. Thousands of euros, base year 2000 .

$L_{t}$ : Total employment ${ }^{3}$, measured in thousands of workers obtained from the Spanish "Encuesta de Población Activa, EPA" published by the Spanish Statistical Institute (INE, 2006).

$K_{1_{t}}$ : Housing Capital Stock Data computed by IVIE and published by BBVA foundation (Mas et al, 2007).

$\bar{K}_{1_{t}}$ : Capital Stock Data excluding Housing Capital Stock, computed by IVIE and published by BBVA foundation (Mas et al, 2007).

All capital stock series are measured in thousands of Euros with base year 2000.

Univariate Analysis. Table 1 contains the values of the augmented Dickey-Fuller (ADF) test for a unit root in first and second differenced series, as well as the ARIMA univariate models. No important outliers have been found; therefore no intervention analysis is needed.

\footnotetext{
${ }^{2}$ All mathematical details have been taken to the appendix.

${ }^{3}$ Ceuta and Melilla employment is not computed to avoid missing data in the first periods of time.
} 
Table 1 Univariate analysis.

\begin{tabular}{|c|c|c|c|c|c|c|c|c|c|c|c|}
\hline \multirow[t]{2}{*}{$\mathrm{ADF}$} & \multicolumn{5}{|c|}{ Lags $(*)$} & \multicolumn{6}{|c|}{ Univariate Models $(* *)$} \\
\hline & 0 & 1 & 2 & 3 & 4 & \multirow{3}{*}{$\nabla y_{t}$} & $\underline{\Phi_{1}}$ & \multirow[t]{3}{*}{$\Phi_{2}$} & \multirow{3}{*}{\multicolumn{2}{|c|}{$\begin{array}{cc}\Phi_{3} & \sigma_{a_{t}}(\%) \\
& 1.33\end{array}$}} & \multirow{3}{*}{$\frac{Q(5)}{2.49}$} \\
\hline$y_{t}$ & -0.87 & -0.60 & -0.77 & -0.64 & -0.46 & & & & & & \\
\hline$\nabla y_{t}$ & -5.91 & -3.44 & -2.69 & -2.71 & -2.62 & & & & & & \\
\hline $\begin{array}{l}l_{t} \\
\nabla l_{t}\end{array}$ & $\begin{array}{l}-0.92 \\
-3.54\end{array}$ & $\begin{array}{l}-1.56 \\
-3.99\end{array}$ & $\begin{array}{l}-1.00 \\
-2.91\end{array}$ & $\begin{array}{l}-0.90 \\
-2.30\end{array}$ & $\begin{array}{l}-0.90 \\
-2.76\end{array}$ & $\nabla l_{t}$ & $\begin{array}{l}0.43 \\
(-0.20)\end{array}$ & \multirow[t]{2}{*}{$\begin{array}{l}-0.35 \\
(0.20)\end{array}$} & \multirow{2}{*}{\multicolumn{2}{|c|}{1.75}} & \multirow[t]{2}{*}{1.36} \\
\hline$\frac{V l_{t}}{k_{1 t}}$ & $\begin{array}{l}-3.54 \\
0.15\end{array}$ & $\begin{array}{l}-3.99 \\
0.69\end{array}$ & $\begin{array}{l}-2.91 \\
0.55\end{array}$ & $\begin{array}{l}-2.30 \\
0.40\end{array}$ & $\begin{array}{l}-2 . / 6 \\
0.61\end{array}$ & \multirow[b]{2}{*}{$\nabla k_{1_{t}}$} & $\frac{(-0.20)}{0.60}$ & & & & \\
\hline $\begin{array}{l}l_{t} \\
\nabla k_{1_{t}}\end{array}$ & -2.95 & -2.07 & -1.76 & -1.78 & -2.00 & & $(0.13)$ & & \multicolumn{2}{|r|}{0.19} & 2.65 \\
\hline$\overline{\bar{k}_{1 t}}$ & -0.53 & -0.26 & -0.25 & 0.00 & 0.02 & \multirow{2}{*}{$\nabla \bar{k}_{1_{t}}$} & 0.56 & & \multirow{2}{*}{\multicolumn{2}{|c|}{0.55}} & \multirow{2}{*}{7.01} \\
\hline$\nabla \bar{k}_{1 t}$ & -2.75 & -2.78 & -2.73 & -3.16 & -3.22 & & $(0.16)$ & & & & \\
\hline
\end{tabular}

Notes: First differences of natural logarithm of the variables in lowercase letters.

(*): $\rho=1$ in $\nabla \mathrm{z}_{\mathrm{t}}=\mu+\rho \mathrm{z}_{\mathrm{t}-1}+\sum_{\mathrm{j}=1}^{\mathrm{p}} \gamma_{\mathrm{j}} \nabla \mathrm{z}_{\mathrm{t}-\mathrm{j}}+\mu_{\mathrm{t}}$. Critical value at $95 \%$ is -1.96 with $\mu=0$ (MacKinnon)

$\left({ }^{* *}\right):\left(1-\sum_{\mathrm{i}=1}^{\mathrm{n}} \Phi_{\mathrm{i}} \mathrm{B}^{\mathrm{i}}\right)\left[\nabla^{2} \ln X_{t}-\mu_{\mathrm{t}}\right]=\mathrm{a}_{\mathrm{t}}$ is the univariate model specification. SD in parenthesis. $\left(\sigma_{a_{t}}\right)$ represents the residual standard deviation and $\mathrm{Q}(5)$ is the Ljung-Box statistic.

Results show that all variables are I(2). The absence of MA terms from univariate models suggest that none of the series seems to be over differenced.

Cointegration. Johansen (1988, 1991) and Granger and Engel (1987) methods were used to study the presence of cointegration relationships among the set of I(1) variables $\left(y_{t}, l_{t}, \bar{k}_{1_{t}}, k_{1_{t}}\right)$.

Results suggest that there is only one cointegration equation $\xi_{t}$, which involves production and employment growth rates.

$$
\xi_{t}=y_{t}-0.47_{(0.05)} l_{t}-0.02_{(0.001)}
$$

Cointegration equation $\xi_{\mathrm{t}}$ can be interpreted as a stable or equilibrium positive relationship between production and employment growth rates, where the disequilibrium in each period $\mathrm{t}$ is measured by $\xi_{\mathrm{t}}$.

\section{Estimation of the Multivariate Model}

Table 2 presents the estimated model (20). Akaike information criterion (AIC) ${ }^{4}$ suggest a VAR(3) process. VEC(2), on twice differenced variables, has been jointly estimated by Generalized Least Squares (GLS). Its corresponding VAR(3) representation appears in Table 2. All non significant parameters have been constrained to be zero.

\footnotetext{
${ }^{4}$ Diagnosis of the process is shown in the appendix III.
} 
Table 2 GLS estimation of process of the VEC(2) in its VAR(3) representation.

\begin{tabular}{c|c|c}
$\widehat{\Pi}_{\mathrm{w}}(\mathrm{B}) \mathrm{w}_{\mathrm{t}}=\mathrm{a}_{\mathrm{t}}$ \\
\hline$\widehat{\Pi}_{\mathrm{w}}(\mathrm{B})$ & $\mathrm{w}_{\mathrm{t}}$ & $\hat{\mathrm{a}}_{\mathrm{t}}$ \\
\hline$\left[\begin{array}{cc}\widehat{\Pi}_{\mathrm{w}_{11}}(\mathrm{~B}) & \widehat{\Pi}_{\mathrm{w}_{12}}(\mathrm{~B}) \\
\widehat{\Pi}_{\mathrm{w}_{21}}(\mathrm{~B}) & \widehat{\Pi}_{\mathrm{w}_{22}}(\mathrm{~B})\end{array}\right]$ & $\left(\begin{array}{c}y_{t} \\
l_{t} \\
\bar{k}_{1_{t}} \\
k_{1_{t}}\end{array}\right)+\left(\begin{array}{c}-0.01 \\
0 \\
0 \\
0\end{array}\right)$ & $\left(\begin{array}{c}\hat{\mathrm{a}}_{y_{t}} \\
\hat{\mathrm{a}}_{l_{t}} \\
\hat{\mathrm{a}}_{\bar{k}_{1 t}} \\
\hat{\mathrm{a}}_{k_{1 t}}\end{array}\right)$ \\
\hline
\end{tabular}

where:

$$
\begin{gathered}
\widehat{\Pi}_{\mathrm{w}_{11}}(\mathrm{~B})=\left(\begin{array}{cc}
1-0.37 \mathrm{~B} & -0.29 \mathrm{~B} \\
0 & 1-1.23 \mathrm{~B}+0.5 \mathrm{~B}^{2}-0.27 \mathrm{~B}^{3}
\end{array}\right) \\
\widehat{\Pi}_{\mathrm{w}_{12}}(\mathrm{~B})=\left(\begin{array}{ll}
0 & 0 \\
0 & 0
\end{array}\right) \\
\widehat{\Pi}_{\mathrm{w}_{21}}(\mathrm{~B})=\left(\begin{array}{cc}
0 & 0 \\
-0.04 \mathrm{~B}+0.04 \mathrm{~B}^{2} & 0
\end{array}\right) \\
\widehat{\Pi}_{\mathrm{w}_{22}}(\mathrm{~B})=\left(\begin{array}{cc}
1-1.6 \mathrm{~B}+0.61 \mathrm{~B}^{2} & 0 \\
0 & 1-1.67 \mathrm{~B}+0.67 \mathrm{~B}^{2}
\end{array}\right)
\end{gathered}
$$

The estimation of equation (6) is:

$$
\widehat{\Sigma}=\left(\begin{array}{cccc}
1.30 \mathrm{E}-04 & 1.46 \mathrm{E}-04 & 4.21 \mathrm{E}-05 & 2.48 \mathrm{E}-06 \\
1.46 \mathrm{E}-04 & 2.53 \mathrm{E}-04 & 5.92 \mathrm{E}-05 & 4.90 \mathrm{E}-06 \\
4.21 \mathrm{E}-05 & 5.92 \mathrm{E}-05 & 2.06 \mathrm{E}-05 & 5.48 \mathrm{E}-07 \\
2.48 \mathrm{E}-06 & 4.90 \mathrm{E}-06 & 5.48 \mathrm{E}-07 & 1.74 \mathrm{E}-06
\end{array}\right)=\widehat{\Pi}_{0, \mathrm{w}}^{*^{-1}} \widehat{\Sigma}^{*} \widehat{\Pi}_{0, \mathrm{w}}^{*-1^{\prime}}
$$

AIC applied to the residuals of the model shows that $a_{t}$ follows a multivariate white noise process.

From $\hat{\Sigma}$ the instant correlation matrix $\hat{\rho}$ can be computed

$$
\hat{\rho}=\left(\begin{array}{cccc}
1 & \mathbf{0 . 8 1} & \mathbf{0 . 8 1} & 0.16 \\
& 1 & \mathbf{0 . 8 2} & \mathbf{0 . 2 3} \\
& & 1 & 0.09 \\
& & & 1
\end{array}\right)
$$

As there are no significant correlations between the housing capital stock and the complementary capital stock, $\mathrm{P}_{\mathrm{k}}=\mathrm{I}$, thus Equation (15) is: 


$$
\widehat{\Pi}_{\mathrm{k}}(\mathrm{B}) \mathrm{k}_{\mathrm{t}}=\widehat{\Pi}_{\mathrm{k}}(\mathrm{B}) \widehat{v}_{\mathrm{k}}(\mathrm{B}) \mathrm{z}_{\mathrm{t}}+\widehat{\alpha}_{\mathrm{k}_{\mathrm{t}}}
$$

From the estimation of Equation (6), $\widehat{\Pi}_{0, \mathrm{w}}^{*}$ can be estimated as

$$
\widehat{\Pi}_{0, \mathrm{w}}^{*}=\left(\begin{array}{cccc}
1 & 0 & -2.07 & 0 \\
& 1 & -2.84 & -1.92 \\
& & 1 & 0 \\
& & & 1
\end{array}\right)
$$

$\widehat{\Pi}_{0, \mathrm{w}}^{*}$ allows estimating (18) from (20). Pre-multiplying (20) by $\widehat{\Pi}_{0, \mathrm{w}}^{*}$ model (18) will be estimated. Table 3 contains the resulting model (18) adjusted to data.

Table 3 Orthogonalized Reduced Form

$$
\widehat{\Pi}_{\mathrm{w}}^{*}(\mathrm{~B}) \mathrm{w}_{\mathrm{t}}=\hat{\mathrm{a}}_{\mathrm{t}}^{*}
$$

\begin{tabular}{c|c|c}
\hline$\widehat{\Pi}_{\mathrm{w}}^{*}(\mathrm{~B})$ & $\mathrm{w}_{\mathrm{t}}$ & $\hat{\mathrm{a}}_{\mathrm{t}}^{*}$ \\
\hline$\left[\begin{array}{lll}\widehat{\Pi}_{\mathrm{w}_{11}}^{*}(\mathrm{~B}) & \widehat{\Pi}_{\mathrm{w}_{12}}^{*}(\mathrm{~B}) \\
\widehat{\Pi}_{\mathrm{w}_{21}}^{*}(\mathrm{~B}) & \widehat{\Pi}_{\mathrm{w}_{22}}^{*}(\mathrm{~B})\end{array}\right]$ & $\left(\begin{array}{c}y_{t} \\
l_{t} \\
k_{1 t} \\
k_{1 t}\end{array}\right)+\left(\begin{array}{c}-0.01 \\
0 \\
0 \\
0\end{array}\right)$ & $\left(\begin{array}{c}\hat{\mathrm{a}}_{y_{t}}{ }^{*} \\
\hat{\mathrm{a}}_{l_{t}}^{*} \\
\hat{\mathrm{a}}_{\bar{k}_{1 t}}{ }^{*} \\
\hat{\mathrm{a}}_{k_{1 t}}{ }^{*}\end{array}\right)$ \\
\hline
\end{tabular}

$$
\begin{gathered}
\widehat{\Pi}_{\mathrm{w}_{11}}^{*}(\mathrm{~B})=\left(\begin{array}{cc}
1-0.37 \mathrm{~B} & -0.29 \mathrm{~B} \\
0.08 \mathrm{~B}-0.08 \mathrm{~B}^{2} & 1-1.23 \mathrm{~B}+0.5 \mathrm{~B}^{2}-0.27 \mathrm{~B}^{3}
\end{array}\right) \\
\widehat{\Pi}_{\mathrm{w}_{12}}^{*}(\mathrm{~B})=\left(\begin{array}{cc}
3.32 \mathrm{~B}-1.25 \mathrm{~B}^{2}-2.07 & 0 \\
4.57 \mathrm{~B}-1.73 \mathrm{~B}^{2}-2.84 & 3.21 \mathrm{~B}-1.29 \mathrm{~B}^{2}-1.92
\end{array}\right) \\
\widehat{\Pi}_{\mathrm{w}_{21}}^{*}(\mathrm{~B})=\left(\begin{array}{cc}
0 & 0 \\
-0.04 \mathrm{~B}+0.04 \mathrm{~B}^{2} & 0
\end{array}\right) \\
\widehat{\Pi}_{\mathrm{w}_{22}}^{*}(\mathrm{~B})=\left(\begin{array}{cc}
1-1.6 \mathrm{~B}+0.61 \mathrm{~B}^{2} & 0 \\
0 & 1-1.67 \mathrm{~B}+0.67 \mathrm{~B}^{2}
\end{array}\right)
\end{gathered}
$$

Table 3 shows dynamic relations among all the variables. As it has been explained in Section II, IRFs can be obtained from the reduced form of model (18) in Table 3 (Equation (2)). By adding up the IRFs, the corresponding Step Response Functions (SRFs) are computed. 


\section{SRFs From the Orthogonalized Reduced Form.}

Table 4 shows the computed responses of output, employment, complementary capital stock and housing capital stock, in percentage points, for each of the following 20 periods, to a permanent, one percentage point increase in the level of housing capital stock. Bootstrap bounds at $80 \%$ confidence level are also provided.

Table 4 Response functions (\%) of each variable level to a permanent unitary shock in housing capital stock

\begin{tabular}{|c|c|c|c|c|c|c|c|c|c|c|c|c|}
\hline \multirow{2}{*}{ Period } & \multicolumn{3}{|c|}{$\ln Y$} & \multicolumn{3}{|c|}{$\ln \mathrm{L}$} & \multicolumn{3}{|c|}{$\ln \mathrm{K}_{1}$} & \multicolumn{3}{|c|}{$\ln \mathrm{K}_{1}$} \\
\hline & LB & $\mathrm{RF}(*)$ & UB & LB & $\mathrm{RF}(*)$ & UB & LB & $\mathrm{RF}(*)$ & UB & LB & $\mathrm{RF}(*)$ & UB \\
\hline 1 & 0.00 & 0.00 & 0.00 & 0.23 & 1.92 & 4.62 & 0.00 & 0.00 & 0.00 & 0.92 & 1.00 & 1.15 \\
\hline 2 & 0.08 & 0.54 & 1.38 & 0.54 & 2.38 & 5.54 & 0.00 & 0.00 & 0.00 & 1.54 & 1.69 & 2.08 \\
\hline 3 & 0.15 & 0.92 & 2.15 & 0.77 & 2.00 & 4.62 & 0.00 & 0.00 & 0.00 & 1.85 & 2.15 & 2.92 \\
\hline 4 & 0.31 & 0.92 & 2.15 & 0.62 & 1.77 & 4.08 & 0.00 & 0.00 & 0.00 & 2.08 & 2.54 & 3.46 \\
\hline 5 & 0.31 & 0.85 & 2.00 & 0.54 & 1.85 & 4.23 & 0.00 & 0.00 & 0.00 & 2.08 & 2.77 & 3.92 \\
\hline 6 & 0.23 & 0.85 & 2.00 & 0.54 & 1.92 & 4.38 & 0.00 & 0.00 & 0.00 & 2.00 & 2.85 & 4.15 \\
\hline 7 & 0.31 & 0.85 & 2.00 & 0.62 & 1.92 & 4.38 & 0.00 & 0.00 & 0.00 & 1.92 & 3.00 & 4.38 \\
\hline 8 & 0.31 & 0.92 & 2.08 & 0.62 & 1.92 & 4.31 & 0.00 & 0.00 & 0.00 & 1.85 & 3.08 & 4.54 \\
\hline 9 & 0.31 & 0.92 & 2.00 & 0.62 & 1.85 & 4.31 & 0.00 & 0.00 & 0.00 & 1.77 & 3.08 & 4.62 \\
\hline 10 & 0.31 & 0.92 & 2.00 & 0.62 & 1.92 & 4.31 & 0.00 & 0.00 & 0.00 & 1.69 & 3.15 & 4.69 \\
\hline 11 & 0.31 & 0.92 & 2.00 & 0.62 & 1.92 & 4.31 & 0.00 & 0.00 & 0.00 & 1.62 & 3.15 & 4.69 \\
\hline 12 & 0.31 & 0.92 & 2.00 & 0.62 & 1.92 & 4.31 & 0.00 & 0.00 & 0.00 & 1.62 & 3.15 & 4.77 \\
\hline 13 & 0.31 & 0.92 & 2.00 & 0.62 & 1.92 & 4.31 & 0.00 & 0.00 & 0.00 & 1.54 & 3.15 & 4.77 \\
\hline 14 & 0.31 & 0.92 & 2.00 & 0.62 & 1.92 & 4.31 & 0.00 & 0.00 & 0.00 & 1.46 & 3.15 & 4.77 \\
\hline 15 & 0.31 & 0.92 & 2.00 & 0.62 & 1.92 & 4.31 & 0.00 & 0.00 & 0.00 & 1.38 & 3.15 & 4.77 \\
\hline 16 & 0.31 & 0.92 & 2.00 & 0.62 & 1.92 & 4.31 & 0.00 & 0.00 & 0.00 & 1.38 & 3.15 & 4.77 \\
\hline 17 & 0.31 & 0.92 & 2.00 & 0.62 & 1.92 & 4.31 & 0.00 & 0.00 & 0.00 & 1.38 & 3.15 & 4.77 \\
\hline 18 & 0.31 & 0.92 & 2.00 & 0.62 & 1.92 & 4.31 & 0.00 & 0.00 & 0.00 & 1.38 & 3.15 & 4.77 \\
\hline 19 & 0.31 & 0.92 & 2.00 & 0.62 & 1.92 & 4.31 & 0.00 & 0.00 & 0.00 & 1.38 & 3.15 & 4.77 \\
\hline 20 & 0.31 & 0.92 & 2.00 & 0.62 & 1.92 & 4.31 & 0.00 & 0.00 & 0.00 & 1.38 & 3.15 & 4.77 \\
\hline
\end{tabular}

Notes: $(*)$ Response functions of natural logarithms of each variable. LB and UB represents the lower and upper Bootstrap Bounds at $80 \%$ confidence level, respectively

Results can be summarized as follows:

1. Output responds to the shock with a lag of one year. The response is positive, a permanent increase in the level of the housing capital stock, leads to a permanent increase in the level of output. This new level is approximately achieved two years after the shock, so it could be said that it is a fast response. The elasticity is not constant over time, two years after the shock the elasticity of output is $0.43(0.92 / 2.15)$ and it decreases to $0.29(0.92 / 3.15)$ nine years after the shock, when it keeps constant. Thus the long-run elasticity can be estimated about 0.29 .

2. Employment reacts more quickly than output, it does it instantaneously. Its response is also positive with a long-run level increase of 1.92 percentage points. This level is attached from the very beginning, however, in order to keep this level, investment in housing capital stock must continue until the housing capital stock to reach its equi- 
librium level (3.15 percentage points over the initial level). Thus, the short-run elasticity decreases from 1.92 at year 1 (the year of the shock) to 0.61 at year 10 (nine years after the shock). Then it keeps constant.

3. No effects on complementary capital stock have been detected. According to this finding both types of capital stocks seems to move independently. The huge aids coming from the European Union together with the well-known "animal preferences for brick" of the Spanish people could be behind this strange result.

4. Effects on production and employment have also feedback effects on housing capital stock. Its equilibrium level is estimated to be two percentage points over the level at the end of the second year. That is, without any feedbacks, the equilibrium level of the housing capital stock should be just one percentage point over the initial one; however, its actual estimated equilibrium level is two percentage points over that.

During the period 2000/05, the levels of output, net employment and housing capital stock grew $16.76 \%, 22.4 \%$ and $19.93 \%$, respectively. Using the long-run elasticity estimated above ( 0.29 for output and 0.61 for labour) the growth in housing capital stock is responsible for the $54.27 \%$ of net employment increase and the $34.48 \%$ of the registered output growth in that period. These figures show the importance of housing as one of the most important engines of growth for the Spanish economy.

\section{Summary and Concluding Remarks}

The importance of housing investment in the past Spanish economic success has been assessed by many economists. However, to find disaggregated econometric estimations of its importance is difficult. This paper deals with this problem and proposes a general conceptual framework for estimating the responses of output and employment to a permanent, one percentage point increase in the level of the housing capital stock.

This conceptual framework has the advantage that does not constrains the statistical properties of the time series used, as well as allows for estimating the structural response functions required in this case. One assumption has been necessary, related with the causal interpretation of possible existing contemporaneous correlations among two sets of variables: output plus labour on one side, and housing capital stock plus complementary capital stock on the other. It has been assumed that both, output and labour can react instantaneously to a shock in any variable of the second set, but none capital stock can react instantaneously to a shock neither in output or labour. None lagged reaction is constrained on a priori grounds.

This only assumption is enough for identifying the structural response functions of output and labour.

Using data for the Spanish economy (1977/05) and standard vector error correction models methodology it has been possible to estimate the importance of the housing capital stock in the recent Spanish economic growth. The results reveal that more than $54 \%$ of net employment created by the Spanish economy, during the period 2000 to 2005 , could be caused, directly and/or indirectly, by housing investment. Also, more than $34 \%$ of output growth accounted in the period could be attributed to the same fact. 
Data support the importance of the Spanish housing investment in explaining the recent, fast growth of the unemployment rate in this economy. Will it be possible for Spain to grow without the help of this important sector? The answer is probably no, at least, in the short or medium term. 


\section{References}

Aschauer D.A. (1989a) Does public capital crowd out private capital? Journal of Monetary Economics, 24,171-188.

Aschauer D.A. (1989b) Is public expenditure productive? Journal of Monetary Economics, 23,177-200.

Granger, C. W. J. and Engle, R. F. (1987) Co-integration and error correction: representation, estimation and testing, Econometrica, 251-276.

Flores, R., Gracia, M., and Perez, T. (1998) Public capital stock and economic growth: an analysis of the Spanish economy, Applied Economics, 30, 985-994.

Jenkins G.M., and Alavi, A.S. (1981) Some aspects of modelling and forecasting multivariate time series. Journal of time series analysis, 2, 1-47.

Johansen S. (1988), Statistical analysis of cointegration vectors, Journal of Economic Dynamics and Control, 12, 231-254.

Johansen S. (1991), Estimation and hypothesis testing of cointegration vectors in gaussian vector autoregressive models, Econometrica, 59, 1551-1580.

Mas Ivars M., Pérez García P. and Uriel Jiménez E. (2007), El stock y los servicios del capital en España y su distribución territorial, Fundación BBVA.

Pereira, A. M. (2000). Is all public capital created equal? Review of Economics and Statistics, 82(3), 513-518, Aug.

Pereira, A. M. and Andráz, J. M. (2005). Public investment in transportation infrastructure and economic performance in portugal, Review of Development Economics 9, 177-96.

Pereira, A. M. and Andráz, J. M. (2010). On the economic effects of investment in railroad infrastructures in Portugal, College of William and Mary, Working Papers in economics, No. 96, Universidade do Algarve, Portugal.

Pereira, A. M. and Flores de Frutos, R. (1999). Public Capital Accumulation and Private Sector Performance. Journal of Urban Economics, 46, 300-22. 


\section{Appendix I. Data}

Table 5 Data. Main aggregated Capital Stock

\begin{tabular}{|c|c|c|c|c|}
\hline Year & GDP & LABOUR & Total Capital Stock & Housing Capital Stock \\
\hline 1977 & 345224904.70 & 12594.38 & 1088822267 & 630209348 \\
\hline 1978 & 350275502.08 & 12398.28 & 1136945841 & 653427037 \\
\hline 1979 & 350421090.30 & 12227.50 & 1180460634 & 674324282 \\
\hline 1980 & 358160891.90 & 11894.90 & 1222594208 & 694412776 \\
\hline 1981 & 357686509.57 & 11588.38 & 1262288977 & 714280016 \\
\hline 1982 & 362144890.88 & 11481.38 & 1301460454 & 733398173 \\
\hline 1983 & 368555294.72 & 11421.70 & 1338247528 & 751074126 \\
\hline 1984 & 375132815.36 & 11118.90 & 1370253267 & 767316317 \\
\hline 1985 & 383841304.58 & 11004.05 & 1404863421 & 783441490 \\
\hline 1986 & 396328894.46 & 11208.80 & 1444999566 & 800036235 \\
\hline 1987 & 418313699.33 & 11749.08 & 1492914843 & 817737561 \\
\hline 1988 & 439624007.68 & 12178.80 & 1550232290 & 838018351 \\
\hline 1989 & 460844793.86 & 12602.55 & 1617434219 & 858814643 \\
\hline 1990 & 478271111.17 & 12922.25 & 1689823644 & 881100978 \\
\hline 1991 & 490447896.58 & 13025.98 & 1761930594 & 901934478 \\
\hline 1992 & 495005204.48 & 12788.80 & 1827833648 & 921293103 \\
\hline 1993 & 489899294.72 & 12259.28 & 1882300510 & 939355043 \\
\hline 1994 & 501574598.66 & 12174.13 & 1937081749 & 956988412 \\
\hline 1995 & 515405414.40 & 12478.00 & 1998114494 & 976110335 \\
\hline 1996 & 527829401.60 & 12835.03 & 2060344847 & 998744557 \\
\hline 1997 & 548234002.43 & 13307.28 & 2126970493 & 1021743374 \\
\hline 1998 & 572809478.14 & 13864.85 & 2205363875 & 1048160664 \\
\hline 1999 & 600008228.86 & 14648.88 & 2295656762 & 1078681111 \\
\hline 2000 & 630262988.80 & 15461.83 & 2393286747 & 1113290418 \\
\hline 2001 & 652600999.94 & 16100.20 & 2494650236 & 1150474529 \\
\hline 2002 & 670092886.02 & 16584.08 & 2597450307 & 1190853874 \\
\hline 2003 & 690183995.39 & 17248.50 & 2705711149 & 1236065097 \\
\hline 2004 & $714.291 .200,00$ & $17.923,25$ & 2818378849 & 1284182883 \\
\hline 2005 & $740.108 .000,00$ & $18.925,10$ & 2943208569 & 1335206417 \\
\hline
\end{tabular}




\section{Appendix II. Mathematical appendix}

From the estimation of $\Sigma=\mathrm{E}\left(\mathrm{a}_{\mathrm{t}}, \mathrm{a}_{\mathrm{t}}^{\prime}\right)$ in (20)

$$
\Sigma=\left(\Pi^{+}(0)\right)^{-1} \Sigma^{+}\left(\Pi^{+}(0)\right)^{-1^{\prime}}
$$

or

$$
\begin{aligned}
\left(\begin{array}{cc}
\Sigma_{11} & \Sigma_{12} \\
\Sigma_{21} & \Sigma_{22}
\end{array}\right) & =\left(\begin{array}{cc}
\mathrm{I} & v_{\mathrm{z} 0} \mathrm{P}_{\mathrm{k}}^{-1} \\
0 & \mathrm{P}_{\mathrm{k}}^{-1}
\end{array}\right)\left(\begin{array}{cc}
\Sigma_{\mathrm{z}} & 0 \\
0 & \Sigma_{\mathrm{k}}^{+}
\end{array}\right)\left(\begin{array}{cc}
\mathrm{I} & 0 \\
\mathrm{P}_{\mathrm{k}}^{-1^{\prime}} v_{\mathrm{z} 0}^{\prime} & \mathrm{P}_{\mathrm{k}}^{-1^{\prime}}
\end{array}\right)= \\
& =\left(\begin{array}{cc}
\Sigma_{\mathrm{z}} & v_{\mathrm{z} 0} \mathrm{P}_{\mathrm{k}}^{-1} \Sigma_{\mathrm{k}}^{+} \\
0 & \mathrm{P}_{\mathrm{k}}^{-1} \Sigma_{\mathrm{k}}^{+}
\end{array}\right)\left(\begin{array}{cc}
\mathrm{I} & 0 \\
\mathrm{P}_{\mathrm{k}}^{-1^{\prime}} v_{\mathrm{z} 0}^{\prime} & \mathrm{P}_{\mathrm{k}}^{-1^{\prime}}
\end{array}\right)= \\
& =\left(\begin{array}{cc}
\Sigma_{\mathrm{z}}+v_{\mathrm{z} 0} \mathrm{P}_{\mathrm{k}}^{-1} \Sigma_{\mathrm{k}}^{+} \mathrm{P}_{\mathrm{k}}^{-1^{\prime}} v_{\mathrm{z} 0}^{\prime} & \mathrm{P}_{\mathrm{k}}^{-1} \Sigma_{\mathrm{k}}^{+} \mathrm{P}_{\mathrm{k}}^{-1^{\prime}} v_{\mathrm{z} 0}^{\prime} \\
v_{\mathrm{z} 0} \mathrm{P}_{\mathrm{k}}^{-1} \Sigma_{\mathrm{k}}^{+} \mathrm{P}_{\mathrm{k}}^{-1^{\prime}} & \mathrm{P}_{\mathrm{k}}^{-1} \Sigma_{\mathrm{k}}^{+} \mathrm{P}_{\mathrm{k}}^{-1^{\prime}}
\end{array}\right)=
\end{aligned}
$$

Then:

$$
\begin{aligned}
\Sigma_{11}=\Sigma_{\mathrm{z}} & +v_{\mathrm{z} 0} \mathrm{P}_{\mathrm{k}}^{-1} \Sigma_{\mathrm{k}}^{+} \mathrm{P}_{\mathrm{k}}^{-1^{\prime}} v_{\mathrm{z} 0}^{\prime} \\
\Sigma_{12}= & \mathrm{P}_{\mathrm{k}}^{-1} \Sigma_{\mathrm{k}}^{+} \mathrm{P}_{\mathrm{k}}^{-1^{\prime}{ }^{\prime} v_{\mathrm{z} 0}^{\prime}} \\
\Sigma_{22} & =\mathrm{P}_{\mathrm{k}}^{-1} \Sigma_{\mathrm{k}}^{+} \mathrm{P}_{\mathrm{k}}^{-1^{\prime}} \\
\Sigma_{\mathrm{z}} & =\Sigma_{11}-\Sigma_{12} \\
v_{\mathrm{z} 0} & =\Sigma_{12} \Sigma_{22}^{-1} \\
\Sigma_{22}=\left(\begin{array}{cc}
1 & 0 \\
-\beta & 1
\end{array}\right)\left(\begin{array}{cc}
\sigma_{\bar{k}_{1}}^{2} & 0 \\
0 & \sigma_{k_{1}}^{2}
\end{array}\right)\left(\begin{array}{cc}
1 & -\beta \\
0 & 1
\end{array}\right) & =\left(\begin{array}{cc}
\sigma_{\bar{k}_{1}}^{2} & 0 \\
-\beta \sigma_{\bar{k}_{1}}^{2} & \sigma_{k_{1}}^{2}
\end{array}\right)\left(\begin{array}{cc}
1 & -\beta \\
0 & 1
\end{array}\right)=\left(\begin{array}{ll}
\sigma_{11} & \sigma_{12} \\
\sigma_{21} & \sigma_{22}
\end{array}\right)= \\
& =\left(\begin{array}{cc}
\sigma_{\bar{k}_{1}}^{2} & -\beta \sigma_{\bar{k}_{1}}^{2} \\
-\beta \sigma_{\bar{k}_{1}}^{2} & -\beta \sigma_{\bar{k}_{1}}^{2}+\sigma_{k_{1}}^{2}
\end{array}\right)
\end{aligned}
$$

Matching terms

$$
\sigma_{11}=\sigma_{\bar{k}_{1}}^{2} ; \sigma_{12}=\sigma_{21}=-\beta \sigma_{\bar{k}_{1}}^{2} ; \sigma_{22}=-\beta \sigma_{\bar{k}_{1}}^{2}+\sigma_{k_{1}}^{2}
$$




$$
\beta=-\frac{\sigma_{12}}{\sigma_{11}}
$$

So all the elements of $\Pi^{+}(0)$ can be estimated across the following relationships

$$
\begin{gathered}
\Pi^{+}(0)=\left[\begin{array}{cc}
\mathrm{I} & -v_{\mathrm{z} 0} \\
0 & \mathrm{P}_{\mathrm{k}}
\end{array}\right] \\
-v_{\mathrm{z} 0}=-\Sigma_{12} \Sigma_{22}^{-1} ; \mathrm{P}_{\mathrm{k}}=\left[\begin{array}{cc}
\frac{1}{\sigma_{12}} & 0 \\
-\frac{\sigma_{11}}{1}
\end{array}\right]
\end{gathered}
$$

Thus, estimating $\Pi^{+}(0)$ across $(21)$ it is possible to estimate $\Pi^{+}(B)$ as $\Pi^{+}(B)=$ $\Pi^{+}(0) \Pi(B)$, and from $\Pi^{+}(B)$ to estimate $\Psi^{+}(B)$ as $\Psi^{+}(B)=\left[\Pi^{+}(B)\right]^{-1}$ 


\section{Appendix III. Diagnosis}

Table 6 Cross Correlation residual function values (CCF)

\begin{tabular}{|c|c|c|c|c|c|c|c|c|c|c|c|c|c|c|c|c|}
\hline lags & 1,1 & 1,2 & 1,3 & 1,4 & 2,1 & 2,2 & 2,3 & 2,4 & 3,1 & 3,2 & 3,3 & 3,4 & 4,1 & 4,2 & 4,3 & 4,4 \\
\hline 1 & 0.21 & 0.29 & 0.20 & 0.18 & 0.07 & 0.16 & 0.15 & 0.32 & 0.13 & 0.13 & 0.11 & 0.26 & 0.06 & 0.12 & 0.25 & -0.26 \\
\hline 2 & -0.03 & -0.01 & -0.04 & 0.01 & -0.07 & -0.01 & -0.08 & -0.04 & -0.08 & 0.00 & -0.15 & 0.01 & -0.02 & -0.16 & -0.14 & 0.14 \\
\hline 3 & 0.02 & -0.05 & -0.11 & -0.42 & -0.13 & -0.22 & -0.30 & -0.20 & 0.11 & 0.05 & 0.06 & -0.12 & -0.16 & -0.08 & -0.27 & -0.10 \\
\hline$\underline{4}$ & -0.18 & -0.11 & -0.36 & -0.04 & -0.37 & -0.18 & -0.38 & -0.12 & -0.18 & -0.04 & -0.23 & -0.10 & -0.01 & -0.02 & -0.06 & 0.10 \\
\hline 5 & -0.19 & -0.09 & -0.11 & -0.22 & -0.24 & -0.21 & -0.19 & -0.14 & -0.32 & -0.28 & -0.37 & -0.11 & -0.02 & 0.03 & 0.16 & -0.17 \\
\hline
\end{tabular}

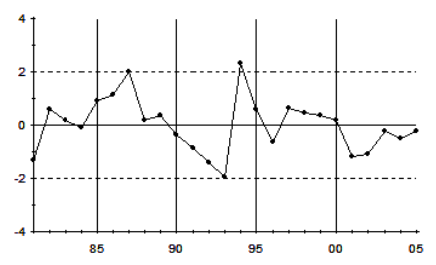

$\overline{\mathrm{w}}\left(\hat{\sigma}_{\overline{\mathrm{w}}}\right)=0.12 \%(0.23 \%) \quad \hat{\sigma}_{\mathrm{w}}=1.13 \%$

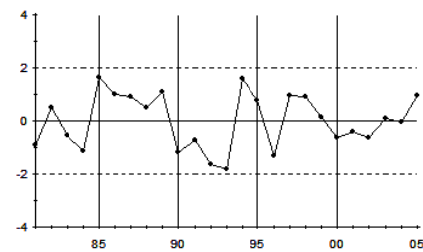

$\overline{\mathrm{W}}\left(\hat{\sigma}_{\overline{\mathrm{w}}}\right)=0.02 \%(0.09 \%)$

$\hat{\sigma}_{\mathrm{w}}=0.45 \%$
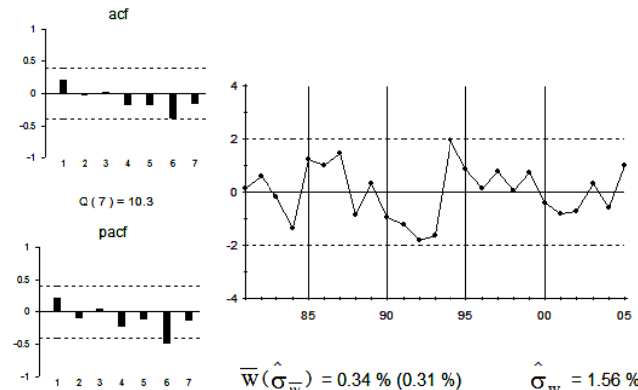

$\overline{\mathrm{w}}\left(\hat{\sigma}_{\overline{\mathrm{w}}}\right)=0.34 \%(0.31 \%)$

$\hat{\sigma}_{\mathrm{w}}=1.56 \%$

acf

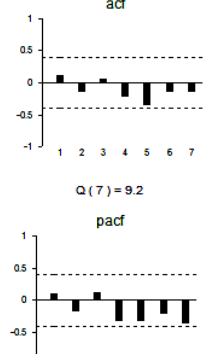

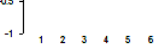

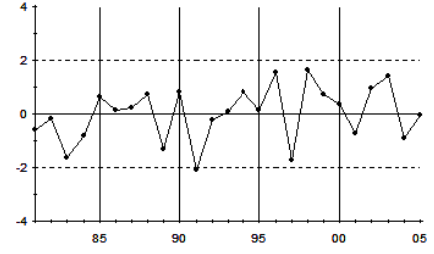

$\hat{\sigma}_{\mathrm{w}}=0.13 \%$

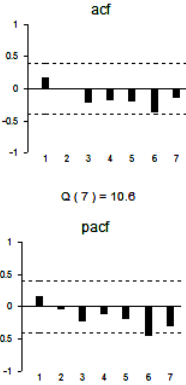

act

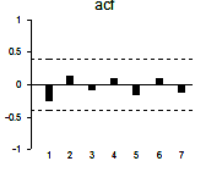

$Q(7)=5.0$

pact

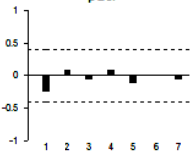

Fig. 1 Residual series and their Autocorrelation (ACF) and Partial Autocorrelation (PACF) functions. 


\section{Appendix III. Cointegration}
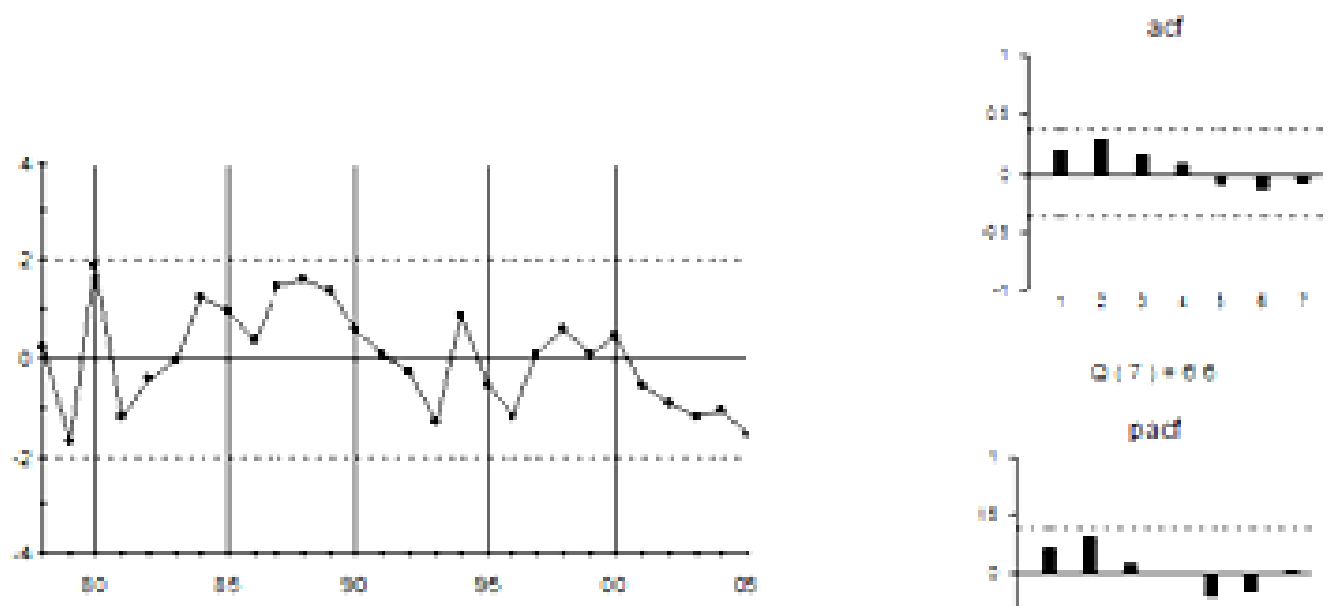

$\bar{w}\left(\sigma_{-}\right)=000 \%(0.15 \%) \quad \sigma_{n-}=079 \%$

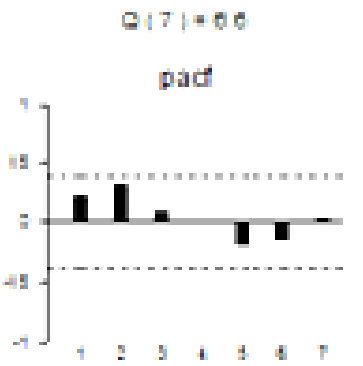

